\title{
Геодинамический мониторинг полуострова Крым с использованием GNSS-, VLBI- и SLR-технологий
}

\author{
А.Е. Вольвач, Г.С. Курбасова, А.И. Дмитроца, Д.И. Неяченко \\ ФГБУН “Крымская астрофизическая обсерватория РАН”, Научный, Крым, 298409 \\ volvach@craocrimea.ru
}

Поступила в редакцию 27 февраля 2018 г.

\begin{abstract}
Аннотация. Геодинамический полигон “Симеиз-Кацивели” включает три взаимодополняющие технологии наблюдений - РСДБ, лазерную локацию ИСЗ и навигационную систему ГЛОНАСС/GPS. Цель программы геодинамического мониторинга полуострова Крым - развертывание многофункциональной региональной системы геодинамического и экологического мониторинга Крыма, использующей GNSS-, VLBI- и SLR-технологии определения перемещений и деформаций земной коры. Составные части: создание системы координатно-временного обеспечения территории Крымского полуострова и осуществление геокинематического мониторинга; геологическое и геофизическое обоснование геокинематической модели; уточнение текущих региональных моделей ионосферы и тропосферы по данным GNSS и других специальных измерений; использование возможностей перманентной ГЛОНАCC/GPS-сети системы для поддержки всех приложений высокоточной геодезической съемки, дифференциальной навигации и других прикладных задач. Задачи системы: обеспечение фундаментальной координатно-временной основы в Крыму с использованием перманентных GNSS-, VLBI- и SLR-наблюдений; непрерывный круглосуточный контроль изменений координат сети ГЛОНACC/GPSстанций, включая референтные станции и роверные приемники, на уровне точности “первые миллиметры - первые сантиметры”; мониторинг как медленных и масштабных тектонических процессов, так и контроля “быстрых” деформаций в локальных сейсмо- и оползнеопасных зонах Крыма.
\end{abstract}

GEODYNAMICAL MONITORING OF THE CRIMEAN PENINSULA USING GNSS-, VLBI- AND SLR-TECHNOLOGIES, by A.E. Volvach, G.S. Kurbasova, A.I. Dmitrotsa, D.I. Neyachenko. The Geodynamical Test Area "Simeiz - Katsiveli" involves three complementary observation technologies VLBI, satellite laser ranging and navigation system GLONASS/GPS. The aim of the program for geodynamical monitoring of the Crimean Peninsula is a deployment of the multi-purpose local system for geodynamical and ecological monitoring of the Crimea using GNSS-, VLBI- and SLR-technologies to detect displacement and deformation of the Earth's crust. Constituents: creation of a system for the coordinate-time monitoring of the Crimean Peninsula and implementation of the geokinematic monitoring; geological and geophysical argumentation of the geokinematic model; improvement of current local models of ionosphere and troposphere according to the data from GNSS and other specific measurements; using of the opportunities of permanent GLONASS/GPS-network of the system to support all applications of the high-accuracy geodetic survey, differential navigation and other applied tasks. Objectives of the system: supporting of the fundamental coordinate-time base in the Crimea by means of permanent GNSS-, VLBIand SLR-observations; continuous 24-hour control of variations in coordinates of the GLONASS/GPSstation network including reference stations and rover receivers at the accuracy level "first millimeters - 
first centimeters"; monitoring of both slow and large-scale tectonic processes and the control of "fast" deformations in local earthquake and landslide zones of the Crimea.

Ключевые слова: геодинамика, координаты, Земля, РСДБ, лазерная дальнометрия

\section{1 Введение}

В настоящее время на территории Крымского полуострова усилиями Крымской астрофизической обсерватории в пгт Симеиз и Кацивели проводятся постоянные измерения внегалактических источников и спутников геодезического класса. Такая измерительная система позволяет обеспечить решение задач на территории Крыма с помощью земной системы координат. Кроме того, такой подход позволяет с высокой точностью привязать и постоянно отслеживать координаты перманентной GPS-станции на базе двухчастотного приемника геодезического класса. На базе использования современных высокоточных GNSS-, VLBI- и SLR-методов определения смещений и деформаций земной коры может быть спроектирована, развернута и проведена экспериментальная отработка региональной системы геодинамического мониторинга Крыма. Такая система позволит решить следующие основные задачи:

- обеспечение фундаментальной координатно-временной основы в Крыму с использованием перманентных GNSS-, VLBI- и SLR-наблюдений;

- обеспечение непрерывного круглосуточного контроля изменений координат сети станций слежения, включая референсные станции и роверные сенсоры на уровне точности “мм-см" в зоне, ограниченной сетью референсных станций;

- обеспечение мониторинга как медленных и масштабных тектонических процессов, так и контроля “быстрых" деформаций в локальных сейсмо- и оползнеопасных зонах Крымского полуострова.

В результате создания региональной системы геодинамического мониторинга в Крыму планируется построить единую геодинамическую модель $3 \mathrm{D}$-движений и деформаций земной поверхности в районе горного Крыма.

На первом этапе проведено развертывание в Крыму специальной сети перманентных референтных ГЛОНАCC/GPS-станций, а также использование наблюдений GNSS-станций, лазерных и интерферометрических наблюдений с целью построения координатно-временной основы на территории Крымского полуострова и обеспечения гарантированного качества геокинематического мониторинга. Полученные данные были использованы в исследованиях тектонического движения плит земной коры и в международных системах координатно-временного обеспечения для построения небесной и земной систем координат. Система геодинамического мониторинга Крыма может также быть использована в международных программах по исследованию тектонических процессов и землетрясений в регионах Черного и Средиземного морей.

Метод РСДБ позволяет достигать точности определения положения станции лучше, чем 0.2 мм (Петров и др., 2001). С целью исследования геодинамических явлений и влияния физических параметров Солнца на состояние экосистемы Земли создан гелио-геодинамический полигон "СимеизКацивели” (рис. 1), имеющий следующие типы наблюдательных средств: РСДБ-станция “Симеиз” на базе телескопа РТ-22, два лазерных спутниковых дальномера (“Simeiz-1873”, "Katsively-1893”) и две станции ГЛОНАСС/GPS (“CrAO", "Katsively”), а также станции мониторинга солнечной активности с помощью радиотелескопов РТ-2, РТ-3 и РТ-М в составе международной сети Службы Солнца.

Все станции космической геодезии и геодинамики входят в состав соответствующих международных служб (Вольвач и др., 2003). Проведенные наблюдения в международной геодинамической сети позволили определить положение РСДБ-станции “Симеиз" с точностью до нескольких миллиметров (Вольвач и др., 2008). Получены следующие координаты РСДБ-станции “Симеиз” на эпоху 1997.0 и скорость их изменения в системе ITRF97: 


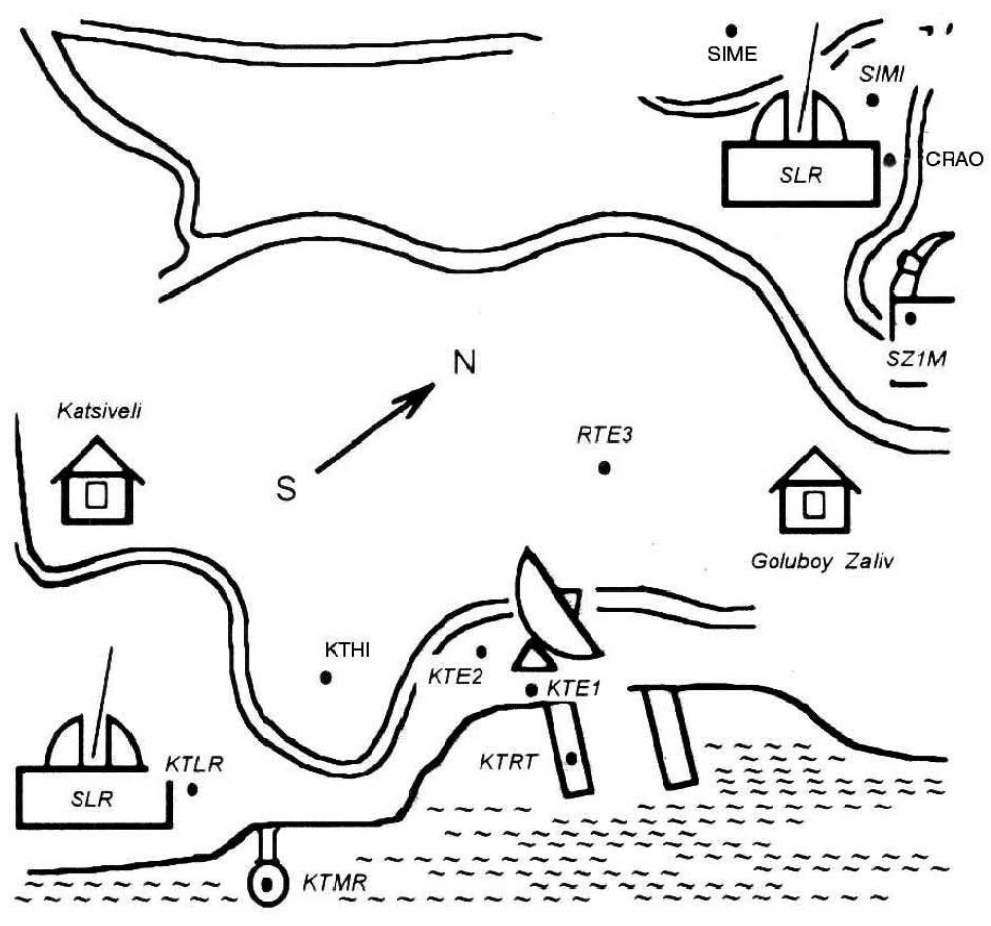

Рис. 1. Геодинамический полигон "Симеиз - Кацивели”

Обозначения: РСДБ-станция “Симеиз”на базе радиотелескопа PT-22; SLR-KTLR - лазерньй cпутниковый дальномер "Katsively-1893"; SLR-SIMI - лазерный спутниковый дальномер "Simeiz1873”; CRAO, KTLR - станциии ГЛОНАCC/GPS; SIME - мобильный лазер; KTMR - датчик уровня моря; KTHI, KTRT, KTE1-3, SZM1 - пункты полигонометрии Государственной геодезической сеmu.

\begin{tabular}{c|c}
\hline Координаты, м & Скорость, м/сек \\
\hline $\mathrm{X}=3785231.070 \pm 0.006$ & $\mathrm{X}=6.8^{-10} \pm 0.3^{-10}$ \\
$\mathrm{Y}=2551207.415 \pm 0.004$ & $\mathrm{Y}=5.0^{-10} \pm 0.4^{-10}$ \\
$\mathrm{Z}=4439796.360 \pm 0.008$ & $\mathrm{Z}=2.1^{-10} \pm 0.8^{-10}$ \\
\hline
\end{tabular}

Возможные локальные систематические эффекты были тщательно исследованы и оценена надежность определения формальных ошибок. Определена абсолютная скорость движения геодинамической станции “Симеиз” в системе ITRF97, равная $32.8 \pm 0.9$ мм/год в северо-восточном направлении (Петров и др., 2001; Вольвач и др., 2009). Определена скорость движения относительно Евразийской тектонической плиты, равная 2.9 мм/год. Станция перемещается в северо-восточном направлении (рис. 2).

Геодинамический полигон “Симеиз-Кацивели” расположен в 300 км от границы Евразийской тектонической плиты. Тектоническое движение в восточном Средиземноморье сложное; оно является результатом взаимодействия Евразийской, Африканской и Аравийской плит. Граница тектонических плит связана с Северо-Анатолийским трансформным разломом. Анатолийский блок движется в западном направлении вдоль разлома (Яцкив и др., 2014). Его толкают в северном направлении Аравийская и Африканская плиты, что вызывает деформацию в южной части Евразийской плиты. Полученная горизонтальная скорость в направлении с азимутом $27^{\circ}$ не противоречит этой модели. 

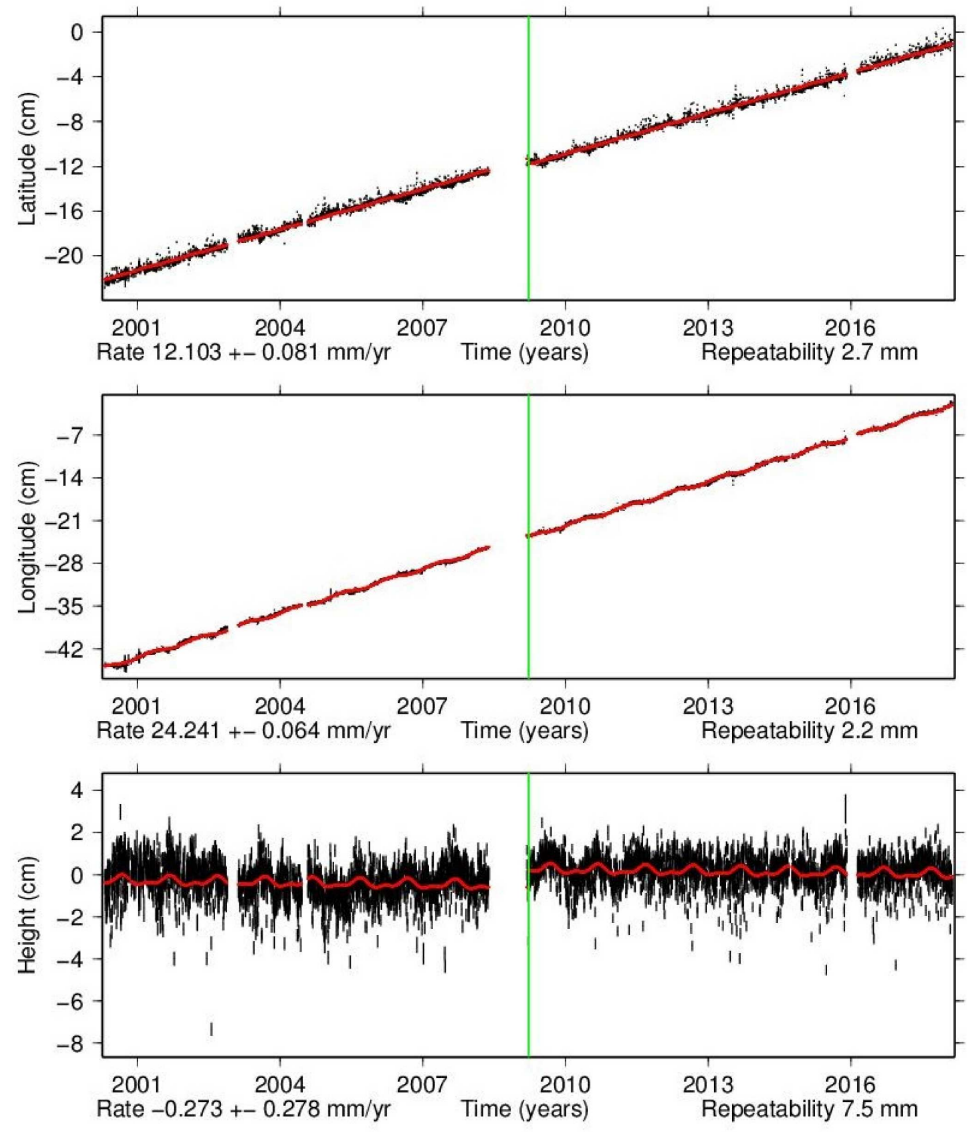

Рис. 2. Скорость движения геодинамической станции “Симеиз"

\section{2 Мониторинг тектонических разломов и современных движений земной коры на Крымском полуострове}

Для мониторинга тектонических разломов и современных движений земной коры на Крымском полуострове предлагается разработать и создать региональную систему детектирования и отслеживания этих геодинамических явлений. Основу такой системы мониторинга будут составлять сети станций высокоточных геодезических и астрономических наблюдений: сети IGS-станций с использованием VRS-технологий (Virtual Reference Station), станции лазерной локации спутников (SLR) и радиоинтерферометр со сверхдлинной базой (VLBI).

Основным назначением региональной системы детектирования и отслеживания геодинамических явлений является:

1. Обеспечение непрерывного круглосуточного контроля изменений координат сети ГЛОНАCC/GPSстанций, включая референсные станции и роверные ГЛОНАCC/GPS-сенсоры, на равные точности “первые миллиметры - первые сантиметры” в зоне, ограниченной сетью референсных станций.

2. Обеспечение мониторинга как медленных и масштабных тектонических процессов, так и контроля “быстрых" деформаций в локальных сейсмо- и оползнеопасных зонах Крымского полуострова.

3. Обеспечение фундаментальной координатно-временной основы Крыма с использованием перманентных GNSS-, VLBI- и SLR-наблюдений.

Данную систему планируется развернуть на существующем Крымском геодинамическом полигоне размером $16 \times 25$ км, расположенном в южной части полуострова, который охватывает территорию 
с горным рельефом. Планируется также создание новых полигонов, которые будут охватывать весь горный район полуострова как зону наиболее опасных геодинамических процессов (землетрясений, сдвигов, обвалов, интенсивных карстовых процессов и др.).

Крымский полуостров состоит из горного Крыма на юге и равнины в северной части полуострова. Горный Крым (150 км от г. Севастополя к г. Феодосии, ширина горной полосы не превышает 50 км) в свою очередь состоит из Главной, Предгорной (Внутренней) и Внешней антиклинальных гряд. Внешняя гряда - наиболее низкая - в северном направлении постепенно переходит в равнину. Внутренняя гряда - высшая, и Главная гряда - высочайшая, ее высоты достигают 1200-1500 м над уровнем моря.

Сейчас в горном районе Крыма находятся две перманентные ГЛОНАCC/GPS-станции (Евпатория, Симеиз), одна РСДБ-станция и две SLR-станции (Кацивели, Симеиз). Данные станции входят в соответствующие международные IGS-, IVS- и ILRS- сети и с помощью них проводятся регулярные наблюдения.

Для реализации построения модели современных движений земной коры в районе горной части Крымского полуострова необходимо создать и развернуть на ней сеть ГЛОНАCC/GPS-станций. Основу этой сети будут составлять 4 реперные станции (2 существующие и 2 новые) и подсистема геодинамических полигонов с GPS-сенсорами. Для привязки этой сети к Международной земной системе координат (International Terrestrial Reference Frame, ITRF) будет использоваться пункт коллокации различных космических методик наблюдений “Симеиз-Кацивели”, в который входят одна VLBI- и две SLR-станции. На сегодняшний день уже осуществлена привязка маркеров этого пункта к ITRF с точностью до 1 см, что недостаточно для мониторинга тектонических разломов и движений земной коры в данном регионе. Необходимо такую привязку осуществить с точностью до 1 мм.

\section{3 Заключение}

Мониторинг геодинамических явлений в Крыму посвящен обеспечению геокинематического и экологического мониторинга Крымского полуострова, исследованию тектонических разломов и современных движений земной коры на полуострове, разработке и созданию региональной системы детектирования и отслеживания этих геодинамических явлений. Непрерывное отслеживание координат фазовых центров приемных антенн GNSS-станций позволит с высокой точностью определить региональные геодинамические эффекты - перемещение земной коры в рамках всего охватываемого региона, позволит делать полномасштабные исследования состояния ионосферы и атмосферы (тропосферы) в регионе, обеспечит поддержку выполнения геодезических и кадастровых работ. Конечным результатом построения такой системы должна стать модель современных движений земной коры в районе горной части Крымского полуострова. Система геодинамического мониторинга Крыма может быть использована в международных программах по исследованию тектонических процессов и землетрясений в регионах Черного и Средиземного морей. Показано, что одним из главных преимуществ системы является многофункциональность, что дает возможность использовать ее не только как мониторинговую систему, но и как систему для поддержки всех возможных приложений, связанных с решением координатно-временных задач (навигация и различные виды геодезических работ) на полуострове Крым.

\section{Литература}

Вольвач и др. (Volvach A., Sokolova Yu., Shabalina O.) // International VLBI Service for Geodesy and Astrometry. 2003. Greenbelt, MD 20771 USA. P. 83.

Вольвач и др. (Volvach A.E., Gor'kavyi N.N., Dmytrotsa A.I., Levitskii L.S.) // Bull. Crimean Astrophys. Obs. 2008. V. 104. Issue 1. P. 145.

Вольвач и др. (Volvach A.E., Gor'kavyi N.N., Dmitrotsa A.I., and Levitsky L.S.) // Bull. Crimean Astrophys. Obs. 2009. V. 105. P. 150

Петров и др. (Petrov L., Volvach A., Nesterov N.) // Kinem. Phys. Celest. Bodies. 2001. V. 17. № 5. Р. 424.

Яцкив и др. (Yatskiv Ya.S., Odynets P.S., Volvach A.E.) // Journées 2013 "Systèmes de référence spatio-temporels" / Ed. Capitaine N. Observatoire de Paris. 2014. P. 216. 